\title{
DISCURSO E PODER: a prescrição do controle corporal em blogs plus size
}

\author{
DISCOURSE AND POWER: \\ the prescription of body control in plus size blogs
}

\author{
Hellen O. Tavares* \\ Ana Lúcia de Castro**
}

\begin{abstract}
Resumo
Buscando contribuir para a compreensão acerca das relações de poder que envolvem os discursos relacionados à obesidade, este trabalho analisa três blogs voltados às mulheres obesas: Mulherão, Beleza sem tamanho e Entre topetes e vinis, conhecidos como "blogs de beleza plus size". Nesses espaços, encontramos a veiculação de um discurso que apregoa um certo orgulho gordo, fornecendo elementos para defesa do direito à diferença representada pela obesidade, mas que, num olhar mais cuidadoso, revela-se reforçador do padrão de beleza hegemônico: defende-se o direito a um corpo obeso, mas não exageradamente, em geral branco, bem cuidado e, acima de tudo, consumidor. Em resumo, uma obesidade aceitável e devidamente adaptada e inserida. Assim, o artigo discute o tipo de significado que estes blogs vêm construindo a respeito do corpo obeso das leitoras, como estes significados estão inseridos na lógica da sociedade capitalista de consumo e, por fim, como as relações de poder atravessam esses discursos.
\end{abstract}

Palavras-chave: Corpo. Obesidade. Cultura de consumo. Discurso.

\begin{abstract}
Seeking to contribute to the understanding of power relations involving the discourses of obesity, this study analyzes two blogs focused on obese women: Mulherão and "Beleza sem tamanho", known as "beauty blogs plus size". In these spaces, we find the placement of a speech that touts a certain fat pride, providing elements for defending the right to represented difference by obesity, but which, on closer look, turns out to be reinforcing the pattern of hegemonic beauty: defends it right to an obese body, but not overly, usually white, well maintained and, above all, consumers. In short, an acceptable and well adapted and inserted obesity. Thus, the article discusses the kind of meaning that these blogs has been building about the obese body of readers, as these meanings are embedded in the logic of capitalist consumer society and, finally, as power relations traverse these speeches
\end{abstract}

Keywords: Body. Obesity. Consumer culture. Discourse.

\footnotetext{
* Doutora em Ciências Sociais/UNESP/Brasil. E-mail: hellenrt@uol.co.br

** Professora do Programa de Pós-graduação em Ciências Sociais da Faculdade de Ciências e Letras, Universidade Estadual Paulista. Doutora em Ciências Sociais/UNICAMP/Brasil. E-mail: castroanalucia75@gmail.com
} 


\section{Introdução}

Nas sociedades ocidentais capitalistas, os corpos se configuram como objetos de consumo e locus preferencial da construção identitária. A magreza e a juventude tornam-se ideais propagados como indicadores de beleza, saúde e bem-estar. A obesidade, ao contrário, é associada à lentidão, à feiura e à doença, características rechaçadas em um contexto em que as noções de velocidade, eficiência e perfeição imperam. Cotidianamente somos seduzidos pelas imagens de mulheres esbeltas nas capas de revistas e comerciais de televisão. Entretanto, o debate sobre a beleza real e o surgimento de uma certa "contra-tendência" - mobilizada especialmente pela internet e representada pelos discursos acerca dos movimentos de fat pride e plus size (ou "orgulho gordo" e "tamanhos grandes") - chama atenção para a maneira como o corpo feminino vem sendo concebido e instrumentalizado, bem como para a influência destes discursos sobre os processos de identificações construídos em torno do corpo obeso.

Estes movimentos, que demandam uma politização do corpo e contestação dos ideais de beleza como sinônimo de magreza, surgiram especialmente pela comunicação através da internet, por meio das mídias sociais que são apropriadas como forma de expressar vozes pessoais não editadas, tornando estas mídias, dentre elas os blogs, instrumentos de reivindicação e construção da própria identidade.

Devemos ressaltar que, assim como outros movimentos, há diversas perspectivas relacionadas ao ativismo antigordofobia. Assim como não é possível falar de uma "mulher universal", ou um "negro universal", não podemos falar de um "gordo universal”. Há homens gordos e mulheres gordas, há gordos e gordas de diversas classes sociais e grupos culturais. Podem ser sedentários, ativos, saudáveis, portadores de comorbidades ou não, com hábitos alimentares considerados saudáveis ou devoradores de fast food. Gordos que querem emagrecer, gordos que querem ser como são. Há gordos e gordas dos mais variados grupos étnicos, de todos os locais do globo, frequentadores das mais diversas religiões, de culturas diferentes, de universos diferentes. Há uma gama inimaginável de pessoas acima do peso e, portanto, uma diversidade de vozes heterogêneas que narram suas experiências pela internet.

Neste trabalho, buscamos compreender um determinado orgulho gordo, encontrado nos chamados "blogs de beleza plus size", que têm se proliferado pela rede e são focados em temas como o mundo da moda, produtos de beleza, tutoriais de maquiagem e penteados, montagens de looks, dicas sobre comportamento, saúde, relacionamentos e viagens, com foco no universo e experiências cotidianas de mulheres que estão acima do peso.

Os blogs escolhidos foram o Mulherão, cuja autora, Renata Poskus, que criou e incentiva a Fashion Weekend Plus Size é, provavelmente, a primeira blogueira plus size do Brasil; o Beleza sem Tamanho, pertencente à blogueira Kalli Fonseca, com cunho de militância política mais presente; e Entre Topetes e Vinis, da blogueira Ju Romano, com tom mais despojado. A pesquisa realizada, de natureza qualitativa, 
situa-se numa perspectiva sócio-antropológica, a partir da qual os blogs foram observados, sistematicamente, entre 2012 e 2015, embora também sejam analisadas postagens anteriores a este período ${ }^{1}$. Durante o período de observação dos blogs, foram selecionadas para análise aquelas postagens que se aproximavam das questões de interesse neste trabalho (insatisfação/aceitação corporal, consumo e experiências cotidianas de mulheres acima do peso). O material selecionado foi submetido a uma análise temática de conteúdo.

Assim, os questionamentos que se buscou responder estão relacionados ao tipo de significados que estes blogs vêm construindo a respeito do corpo obeso das mulheres, como estes significados estão inseridos na lógica da sociedade capitalista de consumo e como as relações de poder atravessam esses discursos.

\section{Blogs plus size e o corpo na cultura de consumo}

Os weblogs, ou simplesmente blogs, são redes sociais que criam espaços de fácil acesso para a escrita e a produção de conteúdos (COBO ROMANÍ; PARDO KUKLINSKY, 2007), em que qualquer pessoa, sem exigência de especialização sobre a área, publica informações, muitas vezes traduzindo-as para o grande público. São recursos tecnológicos que permitem potencializar a geração de comunicação entre pessoas, assim como a participação social e de interatividade por meio da produção e difusão de conteúdos.

Os blogs de moda plus size são, antes de tudo, focados em um pretenso universo de "interesse" das mulheres, como maquiagem, beleza e moda, em que se valoriza a beleza e o corpo da mulher obesa. Os discursos reproduzidos nesses espaços virtuais afirmam que qualquer corpo é belo, e não apenas aqueles considerados pelo discurso hegemônico da magreza das grandes mídias. Esses blogs reforçam, cotidianamente, a importância da autoaceitação e da autoestima da mulher obesa, tentando desconstruir a imagem da mulher obesa como indolente, feia e indesejável. O mote das postagens reside na ideia de que as mulheres gordas são livres para serem quem quiserem, e não devem mais se prender a padrões estéticos.

O blog Mulherão, por exemplo, em sua apresentação, se denomina como "O Manual de Sobrevivência para mulheres acima do peso", se propõe ensinar à mulher obesa formas de ser feliz e se tornar um "mulherão", aceitando e valorizando o próprio corpo.

$1 \mathrm{O}$ endereço do blog Mulherão é: http://blogmulherao.com.br/. O blog Beleza sem Tamanho pode ser encontrado em: http://belezasemtamanho.com/. O endereço do blog Entre Topetes e Vinis é: https:// juromano.com/. 
Figura 1 - Apresentação do blog Mulherão

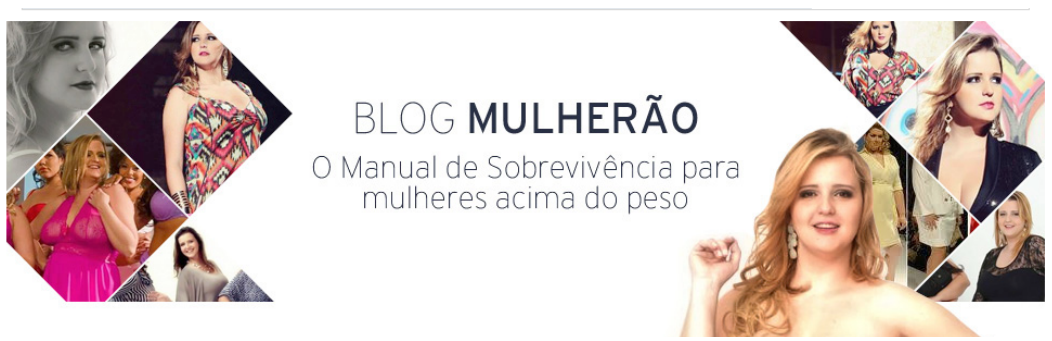

Fonte: https://blogmulherao.com.br. Acesso em: dezembro de 2014

As publicações temáticas deste tipo de blog circunscrevem o tema do corpo obeso, abordando-o de diversas formas, como comportamento, beleza, moda, celebridades plus size, sexo, saúde, preconceito e relacionamentos, sempre tangenciando a esfera do consumo. O principal recurso comunicativo é a imagem, tanto por meio de fotos quanto de vídeos, acompanhados nas postagens por textos curtos, de caráter opinativo ou informativo. O blog é o centralizador de canais em outras mídias sociais, como Instagram, Youtube, Facebook e Twitter, cujos conteúdos complementam o que nele foi postado. Segundo Adriana Amaral, Raquel Recuero e Sandra Montardo (2009), a categoria de blogs que trata sobre estes temas pode ser classificada como um misto de entretenimento, publicação de informações e marketing.

Os blogs têm sido considerados como uma forma de comunicação cuja finalidade é interagir com os utilizadores de internet e os consumidores em escala global. A relação entre os blogs e seus leitores é muito estreita e os blogueiros gozam de grande credibilidade, inclusive no que tange ao incentivo ao consumo, já que a opinião dos leitores é influenciada pela opinião exposta nos blogs. A partir de relatos pessoais, inclusive sobre consumo, os blogueiros se aproximam de seus leitores, gerando identificação e interesse.

Os blogs plus size trazem novidades e informações adaptadas ao contexto do corpo obeso, de forma que os itens apresentados sejam inseridos a um estilo de vida próprio. De acordo com Manuel Castells (1999), as comunidades encontradas na internet se configuram e estabelecem relações da mesma maneira como operam fora do mundo virtual, o que significa que os sujeitos ingressam nessas comunidades e estabelecem vínculos de acordo com seus interesses e valores pessoais. Assim, o principal público frequentador do blog são mulheres adultas, entre 25 e 45 anos, de classe média, com capacidade de consumo e acima do peso, que buscam encontrar produtos e informações a respeito do universo plus size.

Vale destacar, por outro lado, que a internet é uma interessante ferramenta para ampliar e fidelizar os clientes. As redes sociais criam líderes de opinião que intermedeiam a relação entre o mercado e os consumidores. No blog Mulherão, por exemplo, a apresentação de marcas de produtos de moda e beleza, especialmente aqueles voltados para a moda plus size, é recorrente. A blogueira Renata é, inclusive, 
organizadora do maior desfile fashion de marcas de roupas tamanho grande, o Fashion Weekend Plus Size, que ocorre em São Paulo, duas vezes ao ano.

Os blogs são, portanto, fonte de informação sobre produtos que se deseja consumir e sobre quais marcas são alinhadas com o posicionamento de aceitação do corpo obeso por eles propagado. Neste sentido, as fronteiras entre a posição política de aceitação do corpo obeso e do mercado se borram. Tanto as marcas exclusivas para tamanhos grandes como grandes lojas de fastfashion, a exemplo da Marisa, incorporam certos elementos dos discursos antigordofobia e enfocam o nicho de mercado das mulheres acima do peso, tornando-se articuladores de ações que estimulam a autoestima das pessoas obesas e a formação de uma identidade positivada.

Figura 2 - Modelos desfilam coleção plus size da loja Marisa, de incidência nacional, no Fashion Weekend Plus Size

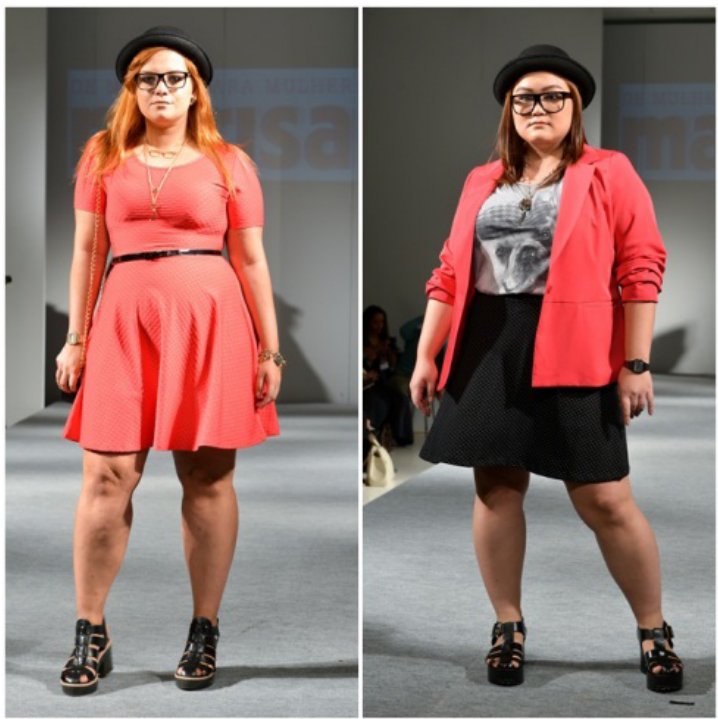

Fonte: https://blogmulherao.com.br. Acesso em: fevereiro de 2015.

A partir das blogueiras, o público se identifica com as marcas, e estas conseguem se inserir na dinâmica deste mercado e ganhar prestígio e fidelidade das compradoras. Jesús Martín-Barbero (1987) aponta que os meios de comunicação interferem (ainda que não determinem) na elaboração das identidades, em um modelo analítico que também considera os conflitos e a dimensão simbólica. Nesta perspectiva teórica, conhecida como teoria das mediações, a relação de dominação não possui um lado passivo e outro ativo, mas relações de poder com abertura para a resistência e a negociação, sendo que as mídias são dispositivos de convencimento, em que a mediação permite a expressão do social, atravessada pela cultura. 
A contemporaneidade é caracterizada por um indivíduo relativamente mais autônomo, que exerce controle sobre suas próprias ações na composição da sua biografia pessoal e autorrealização. Neste sentido, David Le Breton (2003, p. 31) aponta que "o próprio sujeito é o mestre-de-obras que decide a orientação de sua existência”. Podemos pensar os blogueiros influentes, como Renata Poskus, Ju Romano e Kalli Fonseca - respectivamente dos blogs Mulherão, Entre Topetes e Vinis, e Beleza sem Tamanho - como sujeitos que corporificam valores, se apresentando como intermediárias entre as leitoras e o mercado, permeadas por um discurso que remete a um certo ativismo político em prol da aceitação do corpo gordo.

Assim como os ídolos famosos das capas de revistas, os blogueiros com grande número de seguidores são admirados e possuem alta popularidade. Fred Inglis (2012), ao falar sobre as celebridades, aponta que os ídolos apresentam um estilo de vida, uma forma de estar no mundo que influencia a forma como seus admiradores constroem seus valores. Nos blogs, é comum encontrar comentários de leitores que se sentem "amigos" dos blogueiros, acompanham suas trajetórias pessoais e se identificam com o discurso produzido, uma vez que a imagem desses sujeitos públicos cria uma espécie de sensação de pertencimento.

Figura 3 - Leitora comenta participação das blogueiras em programa de televisão e demonstra sentimento de "amizade virtual". Comentário da postagem

"Moda é coisa de gente fútil", de março de 2014

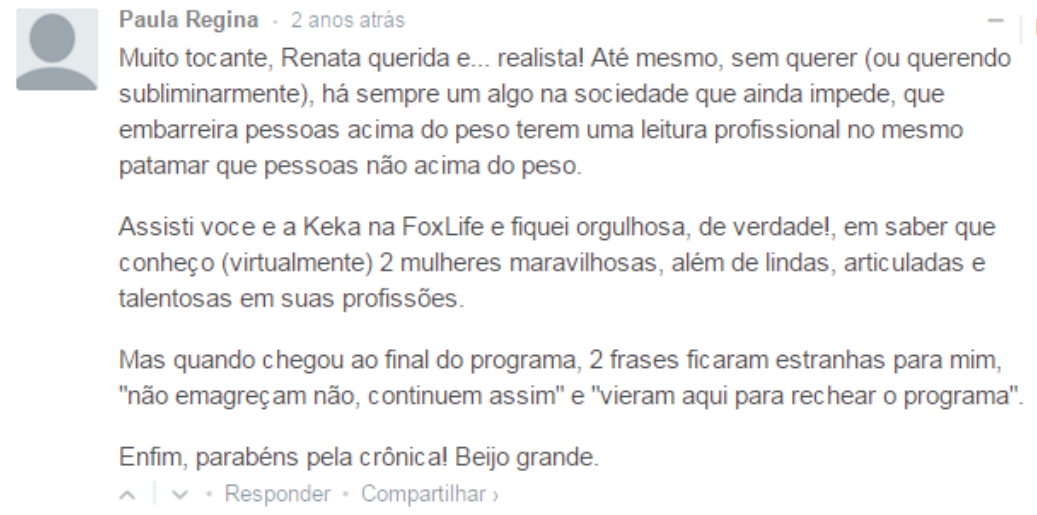

Fonte: https://blogmulherao.com.br/. Acesso em: março de 2014

As imagens públicas dos blogueiros incorporam significados de sua época, como sucesso, riqueza, generosidade, espontaneidade e simpatia (INGLIS, 2012, p. 27). Para Zygmunt Bauman (2008), as redes sociais satisfazem uma necessidade contemporânea de intercâmbio de informações pessoais, em que os usuários desejam revelar detalhes íntimos. Os blogs simulam um modo de expressão 
baseado na publicização de si, em uma relação construída entre enunciador e coenunciador de maneira pessoal. A imagem pessoal construída nas redes sociais promove uma mercadoria sedutora e desejável. Ao longo das postagens, as autoras dos blogs vão delineando sua imagem como mulher obesa bem-sucedida. No blog Mulherão, a autora se descreve como jornalista, escritora, consultora de moda, modelo plus size, empresária, blogueira e criadora do Dia de Modelo, o Fashion Weekend Plus Size e da Loja Mulherão Online. Suas fotografias mostram uma mulher poderosa e decidida, uma "mulher com 'm' maiúsculo", como se apresenta em sua autodescrição².

Figura 4 - a) A criadora do blog, Renata Poskus na postagem "Como me tornei uma modelo plus size", de abril de 2015, b) Renata posa em

Editorial Plus Size, em setembro de 2015
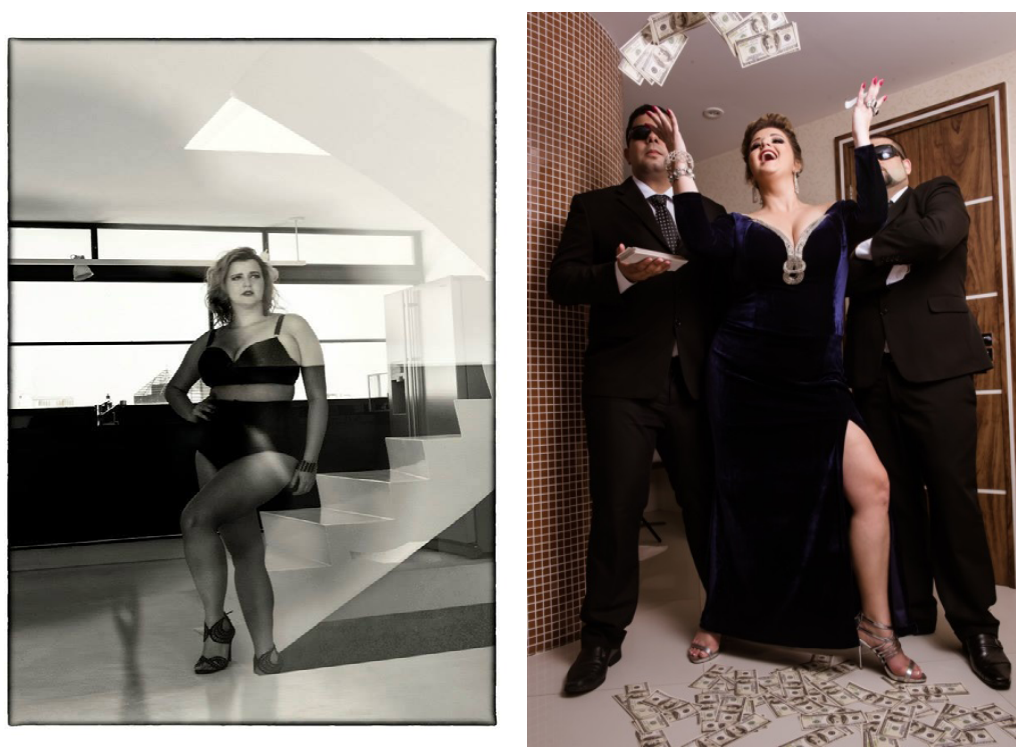

Fonte: https://blogmulherao.com.br. Acesso em: setembro de 2015.

\footnotetext{
2 A autora se apresenta como "Renata Poskus: paulistana, criadora do Blog Mulherão. Jornalista, escritora, cronista, consultora de moda, modelo plus size, empresária, assessora para assuntos aleatórios, mulher com 'm' maiúsculo, viciada em temas pertinentes ao universo feminino. Há um bom tempo acima do peso. Quase sem neuras. Eu disse quase, não se iludam!”. Disponível em: <http://blogmulherao.com.br/o-blog/>. Acesso em: dez. 2015.
} 
Os blogueiros, como figuras públicas, surgem como força integradora que determina a forma como as leitoras significam suas realidades, e consequentemente, seus corpos. Para Rojek (2008), celebridades mantêm uma imagem pública encenada, um espetáculo que valoriza o superficial, com ênfase no consumo e no culto à beleza e ao corpo. As blogueiras plus size realizam uma mediação entre o mercado e suas leitoras/consumidoras, que comumente disseminam uma cultura de consumo, a qual aprisiona e controla os sujeitos.

Ao considerarmos o blog como um meio de comunicação, podemos pensálo como um dispositivo de convencimento (MARTÍN-BARBERO, 1987), havendo participação de seu público na construção de sua imagem pública como mulher admirada. As blogueiras aparecem como produtoras de sentidos, corporificando características importantes para a cultura de consumo, como carisma, sucesso, riqueza e beleza. Seu corpo obeso, desejado e invejado, é considerado um modelo de beleza natural, poder e sensualidade. Suas imagens tornam-se um espelho, no qual suas leitoras se refletem. Sua atuação no blog ajuda a filtrar as apropriações sobre o corpo obeso e o reconhecimento de uma identidade plus size em que o corpo gordo é visto positivamente, e não como sinônimo da exclusão e do estigma.

As imagens do corpo gordo produzidas e reproduzidas nos blogs não dizem respeito diretamente à conquista de possíveis consumidores, mas à construção de um determinado estilo de vida, de uma imagem ideal do que é ser uma mulher gorda. São também aos sentidos produzidos em um sistema de significação que remete à própria sociedade do consumo, para além do que se mostra. A mensagem transmitida é daquilo que está sendo mostrado e vendido, é o que todos almejam alcançar. A partir disso, cada indivíduo buscará a sua identidade dentro de uma gama de signos e ideais de referência gerados e que representam um determinado código social. Ao se parecerem com as blogueiras, representantes idealizadas do corpo gordo - seja vestindo-se como elas, utilizando os mesmos produtos de beleza, o mesmo corte de cabelo ou mesmo reproduzindo suas opiniões -, suas seguidoras aderem a um determinado grupo de ideais e valores. Cada postagem ou foto publicada é carregada de significados e possibilidades.

Não sem sentido, os blogueiros, instabloggers, youtubers, entre outros produtores de conteúdos online, têm sido chamados de "influenciadores sociais", e são vistos como pontes entre as empresas e os seus seguidores. Para as marcas, a influência social abre espaço para uma maior capitalização de mercado, e ainda atinge públicos que de outra maneira seriam inacessíveis. Os influenciadores são porta-vozes das novidades de seu meio, e estão nas redes sociais emitindo posicionamentos, ou seja, são aqueles que transmitem uma mensagem que tem impacto nas ideias e práticas de outras pessoas. Blogueiros com maior influência são celebrizados por seu sucesso na internet, e estão sempre próximos de seu público, uma vez que os relacionamentos na rede são pautados na agilidade e na interatividade. 
Figura 5- Comentários na Fanpage do Facebook do Blog Mulherão, sobre um ensaio sensual feito pela blogueira Renata Poskus, publicado na postagem "Meu ensaio sensual geek plus size pela Naked Fotografia", em junho de 2015
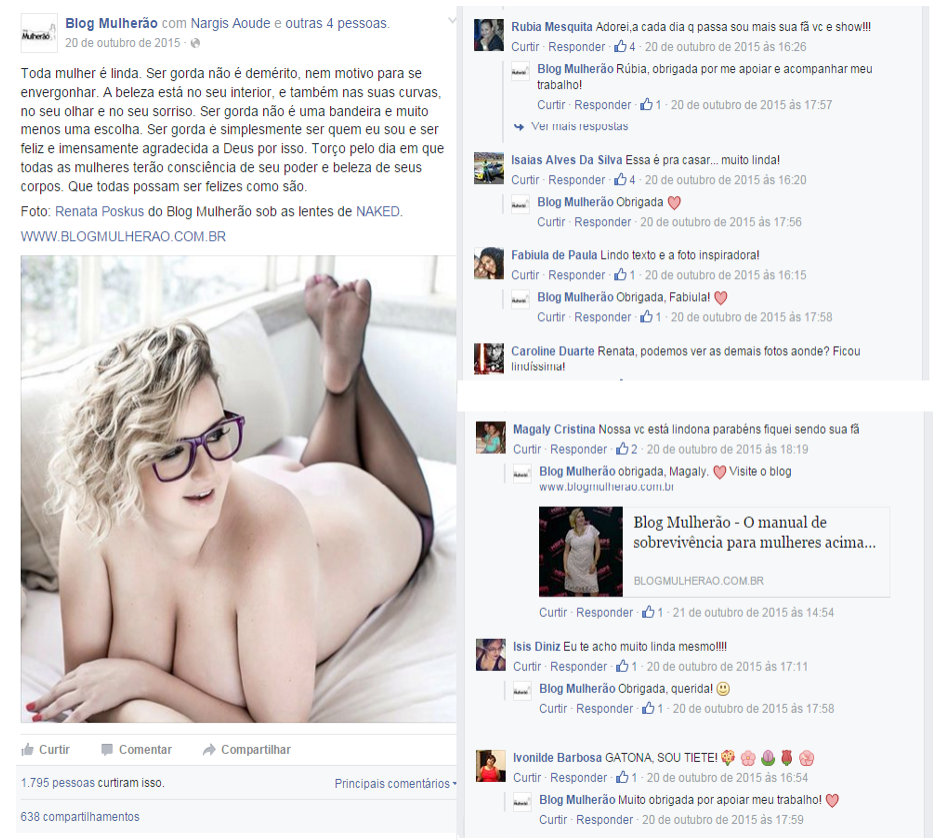

Fonte: Página do facebook do blog Mulherão. Acesso em: outubro de 2015.

Há milhões de blogs, criados em diversas operadoras ao redor do mundo, e representam, assim como outras mídias, os processos de significação e as redes de poder da sociedade contemporânea, articulando saberes a respeito dos significados do corpo e de formas de ser e estar no mundo. Os conteúdos desses espaços virtuais são resultados das práticas discursivas, às quais fazem parte da cultura em que os sujeitos estão inseridos.

Podemos considerar a internet, entre outras coisas, como um artefato cultural que educa e molda os corpos, dita comportamentos e formas de ser. Conforme Rosângela Soares e Dagmar Meyer (2003, p.136), problematizações como essas "podem ser produtivas para se pensar como os artefatos culturais revistas, programas de televisão e filmes, por exemplo - estão ajudando a constituir formas de ser e viver, na contemporaneidade". Neste sentido, podemos entender os blogs como artefatos culturais que produzem significados e ensinam determinados comportamentos.

Assim, podemos compreender o conteúdo desses blogs plus size a partir das experiências, práticas e crenças lá compartilhadas, como parte dos sistemas 
de significação, estruturas de poder e instituições sociais. As blogueiras plus size representam o perfil e o estilo que deve ter uma mulher obesa e, como pessoas públicas e influentes, fazem parte do imaginário e representações socioculturais e mercadológicas sobre o corpo gordo. Cabe, portanto, compreender como os discursos sobre o corpo da mulher obesa são construídos nos blogs plus size.

\section{Corpo: constructo histórico-cultural}

O corpo, desde o nascimento, é educado e, como bem demonstrou Marcel Mauss (2003) em suas pioneiras reflexões, os códigos culturais de cada sociedade se revelam nos cuidados com o corpo. As concepções sobre o corpo, especialmente o feminino, estão em constante mudança, e seus ideais modificam-se de acordo com os interesses presentes em cada período histórico. O corpo, como aponta Mary Del Priore (2000), é um produto cultural e histórico que se fragmenta e recompõe ao longo do tempo, ou seja, ele é social e cultural e, portanto, deve ser relativizado quanto a seu contexto. Felix Guattari e Suely Rolnik (2000, p. 278) afirmam que "nos atribuem um corpo, produzem um corpo para nós, um corpo capaz de se desenvolver num espaço social, num espaço produtivo, pelo qual somos responsáveis". O corpo é investido de cultura, revela hábitos e costumes, se modifica ao longo dos processos sociais. O corpo revela mais do que um invólucro, expressa comportamentos e valores de uma dada sociedade. Ao observarmos culturas e sociedades distintas ao longo da história, percebemos, também, corpos distintos.

As representações de beleza, necessariamente histórico-culturais, se modificam ao longo do tempo, em cada sociedade. Desde a Antiguidade, os indivíduos se valem de artifícios para promover ou manter a beleza corporal. Os primeiros recursos relacionados à maquiagem datam de 5000 a.C. Em 1300 a.C., as mulheres egípcias tinham vários cuidados em relação ao corpo (ROUSSO, 2000).

No período do Renascimento, na Europa, a partir do século XV, as mulheres tinham, predominantemente, formas opulentas, com ancas largas e seios fartos, e os corpos gordos eram admirados. Na Idade Moderna, com o modelo cartesiano que substitui a fé pela razão, surge um modelo que separa mente e corpo, e este passa ser visto a partir de sua funcionalidade técnica e útil (ULLMANN, 2004).

Se a ciência e a moral modernas baseiam-se, sobretudo, nos ideais iluministas, cartesianos e sanitaristas, o conceito de beleza das sociedades capitalistas deve também ser compreendido a partir destes preceitos. De tal maneira, a beleza é associada a tudo aquilo que é considerado proporcional, equilibrado, harmônico e limpo. Esta associação vem sendo operada desde o Renascimento, quando foram resgatados os valores estéticos e morais da Antiguidade Clássica, momento em que o belo era considerado como algo de existência objetiva, ordenada, racional e universal.

Com o advento da Revolução Industrial, um novo ethos social começa a se formar, marcado pela crença no progresso e nas novas conquistas da ciência, que difundia práticas de "higienização" e comedimento no uso dos corpos. O corpo revela em seus gestos, que são aprendidos e internalizados, a história da sociedade a qual pertence, revelando regras e costumes de ordem social. Para Soares, 
A ciência deste período dirige um certo tipo de esquadrinhamento da vida em todas as suas dimensões, pretendendo estabelecer uma ordem lógica nas atividades e um adequado aproveitamento do tempo ou, mais precisamente, uma economia de energias. A ginástica é constitutiva desta mentalidade. Destaca-se pelo seu caráter coordenativo, disciplinador e metódico (SOARES, 2005, p. 19).

Os saberes e técnicas do início do século XX, em relação ao corpo, começam a se sofisticar com a "intenção de livrar os corpos das doenças, promover a disciplina alimentar, numa palavra, controlar os corpos não apenas para bem administrar uma cidade, mas, igualmente, para obter mais saúde e prazer" (SANT'ANNA, 2001, p. 4). Joana Vilhena Novaes (2005) mostra que os sujeitos, em especial as mulheres, lutam contra seu próprio corpo, seu envelhecimento e sua forma natural, em prol de manter um determinado padrão de beleza, "se antes as roupas as aprisionavam, agora se aprisionam no corpo - na justeza das próprias medidas” (NOVAES, 2005, p. 33).

O corpo seria o primeiro lugar em que se estabelecem os limites sociais e psicológicos, onde a cultura inscreve todos os seus significados. Para Michel Foucault, o controle social sobre os indivíduos começa pela concretude do corpo:

o controle da sociedade sobre os indivíduos não se opera simplesmente pela ideologia, mas começa no corpo, com o corpo [...] foi no biológico, no somático, no corporal que antes de tudo investiu a sociedade capitalista. O corpo é uma realidade biopolítica (FOUCAULT, 2004, p. 80).

Na contemporaneidade, os modelos de corporeidade estão, cada vez mais, relacionados às novas formas de subjetivação, intermediadas pela mídia, que como instância socializadora, propicia aos corpos, especialmente os femininos, a incorporação de certa normatização, em que discursos e práticas culturais relativos aos corpos são naturalizados e racionalizados. Como decorrência deste processo erige-se, por exemplo, a ideia de que a beleza e a vaidade são características intrinsecamente femininas.

Para Del Priore (2000, p. 92), a indústria cultural ensina para mulheres que "cuidar do binômio saúde/beleza é o caminho seguro para a felicidade individual. É o culto ao corpo na religião do indivíduo em que cada um é simultaneamente adorador e adorado". O pós-guerra é analisado por Ana Lúcia de Castro (2008) como um ponto de inflexão na relação dos indivíduos com seus corpos, momento em que o culto ao corpo ganha novos contornos, impulsionado pela cultura de consumo e criando as condições para a proliferação das academias de ginástica e a consequente cultura fitness, na qual "malhar" torna-se um imperativo:

É curioso observarmos que o momento em que o culto ao corpo ganha espaço no interior da vida social é, coincidentemente, próximo do apontado como o ponto de inflexão das sociedades capitalistas ocidentais, que passam a ter uma nova configuração. Se a modernidade, a partir do pós-guerra, entra numa nova etapa e ganha contornos diferenciados, o mesmo ocorre ao culto ao corpo, ou à relação dos indivíduos com seus corpos (CASTRO, 2008, p.3). 
Neste contexto, o cinema traz atrizes com corpos pequenos e curvilíneos, e os gestos tornam-se mais delicados. A partir da década de 1960, os corpos emagrecem e começam a representar elegância e poder, e as curvas começam a desaparecer dando espaço a um corpo esguio e retilíneo. Nos anos 1970, corpos excessivamente magros aparecem como objeto de desejo. Na década de 1980, despontam tratamentos estéticos, intervenções cirúrgicas e dietas alimentares que tentam garantir o alcance do padrão de beleza. Na década de 1990, as supermodelos viram ideal de beleza com seus corpos inatingíveis.

Kate Moss, ressuscitou a fragilidade física de Twiggy, desta vez com causa identificada: anorexia. A doença se alastra pelas passarelas e segundo os médicos, tem relação direta com a compulsão estética de um corpo magro estipulado às mulheres (ULLMAN, 2004, p. 96).

O corpo modelado nas academias aparece como o triunfo sobre a natureza. A exibição dos corpos revela "os signos de uma nova moralidade, que, sob a aparente libertação física e sexual, prega a conformidade a determinado padrão estético, convencionalmente, chamado de 'boa forma"' (GOLDENBERG; RAMOS, 2002, p. 24-25). Surgem discursos que levam os sujeitos, especialmente as mulheres, a adotarem práticas corporais que incluem disciplinas rigorosas de alimentação e realização de atividades físicas, além de intervenções e tratamentos estéticos. A maior parte das mulheres investe grande parte de seu tempo em cuidados com o corpo, em prol de aperfeiçoá-lo e modelá-lo. Anseiam por um corpo disseminado nas mídias: magro, jovem e, muitas vezes, inatingível.

Nesse contexto, um corpo modelado passa a ser cada vez mais uma exigência. A pressão é exercida desde a infância, em um processo que realmente educa o corpo para a beleza. Em vez de brincar ou estudar, as meninas são incentivadas a usar batons e não engordar. As meninas aprendem a controlar e alterar o próprio corpo para atingir uma aparência perfeita.

As bonecas que imitam bebês perdem espaço, e as bonecas "manequim", que valorizam as formas físicas e esguias ganham popularidade. O objetivo da brincadeira não é mais cuidar e alimentar uma boneca que representa uma criança, mas ser uma mulher adulta bela. A boneca "Barbie", referência de beleza no mundo ocidental, foi criada no contexto pós-guerra, incentivando o consumismo capitalista, popularizando seu padrão corporal.

Estima-se que, desde a sua criação, um bilhão de bonecas Barbies foram vendidas em mais de 150 países [...] Com o status de boneca mais vendida do mundo, seu sucesso é sempre vinculado à beleza, à juventude e ao consumo. Devido às diversas adaptações visuais e à representação de diferentes etnias, a boneca norte-americana acompanhou as mudanças de tendência em moda, beleza e comportamento e construiu uma memória da cultura ocidental (CECHIN; SILVA, 2012, p. 2). 
O advento do consumo de massa e a necessidade do aumento do consumo também estimulam uma mudança nos hábitos das mulheres. A mídia e as revistas femininas estimulam regimes e métodos para atingir a beleza, que é, cada vez mais, magra e jovem. A aparência corporal torna-se mais um fator de marginalização de alguns grupos. Para Del Priore (2000, p. 92):

[...] Mas o culto não é para todos. O tal corpo adorado é um corpo de "classe". Ele pertence a quem possui capital para frequentar determinadas academias, tem personal trainer, investe no body fitness; esse corpo é trabalhado e valorizado até adquirir as condições ideais de competitividade de que lhe garanta assento na lógica capitalista. Quem não o modela, está fora, é excluído (DEL PRIORE, 2000, p. 92).

O ideal de corpo está, portanto, diretamente relacionado aos fatores socioculturais e interesses econômicos que alargam ou estreitam as fronteiras do corpo de acordo com o interesse dos grupos dominantes. As imagens do feminino são constantemente associadas à beleza e à obsessão em alcançá-la, especialmente por meio do consumo, que em certos momentos trata as mulheres como consumidoras, e em outros como objetos de consumo.

Ainda que o final do século XX e início do século XXI sejam marcados por uma obsessão coletiva pela magreza, e um consequente repúdio ao corpo gordo, que atravessa toda a cultura ocidental, e que o corpo gordo nunca tenha parecido ser tão rechaçado e evitado, seja em prol da saúde ou da beleza, surgem os discursos contrários ao costumeiramente posto nas sociedades que cultuam os corpos magros, entre eles, os encontrados nos blogs plus size.

\section{Blogs Plus Size: o cuidado de si e a valorização do corpo obeso}

É preciso considerar que os sujeitos não absorvem as transformações da sociedade de forma passiva e acrítica, sendo palco para paradoxos e conflitos, em que se busca a singularidade ou se tenta negar a diferença e alteridade dos corpos. Para Novaes (2005, p. 74), "como todo culto, toda moda, o impacto da moda do culto ao corpo sobre a sociedade só pode ser detectado a partir da compreensão da maneira como seus ditames são interpretados pelos indivíduos que, no interior de diferentes grupos sociais, lhe emprestam significados próprios".

A criação de discursos sobre corpos hegemônicos e desviantes está inserida em uma relação de poder, que é instável e expressa uma constante disputa. Os grupos sociais são significados e representados no interior dessas relações de poder, em que os corpos são construídos e reconstruídos nos discursos, e adquirem materialidade.

Para Raymond Williams (1979), a hegemonia é um processo ativo, mesmo que não seja sempre dominante, já que não se pode esgotar as práticas e intenções humanas, havendo na prática, sempre espaço para resistências, disputas, subversões e surgimento de novos significados e valores, ainda que estes processos sejam limitados pela própria cultura. 
Nos blogs de moda plus size, a questão política que se problematiza é a correlação entre gênero, corpo e obesidade. Os corpos femininos parecem, nos últimos anos, estar inscritos em uma rede mais aberta de discursos e saberes que permitiram a introdução e a propagação de outros modelos de vivência para a experiência do corpo obeso. Prega-se nestes espaços, a "livre escolha" no que diz respeito ao próprio corpo, seja na forma de cuidá-lo, de como exercer a sexualidade, vestir-se, quando e como apresentá-lo.

Estes saberes, todavia, regulam e controlam o corpo biológico e a intimidade das mulheres, dirigindo seus comportamentos, ao mesmo tempo em que parecem criar um sentimento de "autonomia", em que essas mulheres seriam donas de si, de seus corpos e de seus gostos. Frases como "seja quem quiser", "faça o que quiser", "use o que quiser" são recorrentes nos blogs plus size, sempre aludindo a uma certa autonomia que as mulheres deveriam ter, ainda que sendo gordas.

Figura 6 - Postagem do blog Beleza sem Tamanho, de setembro de 2015, sobre autoestima e aceitação

12.09.15 ACEITAÇÃO AUTOESTIMA COLUNISTAS GORDA

\section{GORDAS PODEM TUDO}

E quando eu digo tudo, é tudão mesmo! Você pode ser feliz, amada, desejada, linda,ousada,estilosa, sedutora,sexy, invejável,yogi, atleta,dançarina, empoderada, dentre tantas outras coisas que qualquer mulher pode ser. Você pode! Você consegue! Acredite mais em você e duvide das opiniões negativas que só te colocam pra baixo! Aprenda e entenda que se alguém não te aceita, essa pessoas simplesmente não te merece! E seu valor não está no fato de estar ou não num relacionamento com alguém. Você não é definida por números, sejam eles da balança ou de redes sociais.

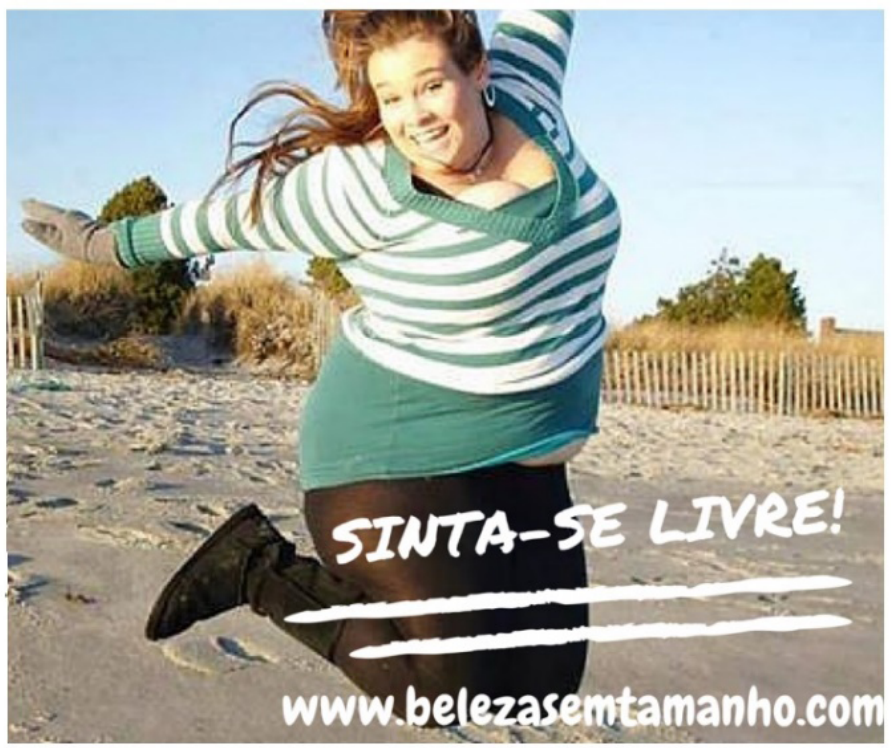

Fonte: http://belezasemtamanho.com. Acesso setembro de 2015. 
As questões que se colocam diante destas frases ("gordas podem tudo" e "sinta-se livre", apresentadas na figura anterior) são se realmente estes blogs desconstroem as relações de poder, se estas mulheres realmente são donas de seus corpos e se agem, de fato, de maneira livre e autônoma. A construção do corpo é uma construção social e linguística, produto e efeito das relações de saber-poder como demonstra Foucault (1999). O obeso, portanto, também está inserido em formas de regulação social permeadas por relações culturais e históricas de saber e poder, pois a subjetividade se constrói no interior de processo sociais. Em resumo, os discursos nos blogs não são neutros e produzem efeitos na vida das mulheres obesas.

As práticas corporais apresentadas e incentivadas nos blogs de moda plus size também fazem parte da trama cultural confirmando o apontado por Foucault (2004, p. 27):

[...] pensamos que o corpo tem apenas as leis de sua fisiologia e que ele escapa à história. Novo erro; ele é formado por uma série de regimes que o constroem; ele é destroçado por ritmos de trabalho, repouso e festa; ele é intoxicado por venenos - alimentos ou valores, hábitos alimentares, e leis morais.

Os blogs plus size propõem um redescobrimento dos corpos, propõem um olhar diferente daquele da exclusão, do constrangimento e do conformismo com um corpo que não se adapta. Eles sugerem que o corpo gordo também deve ser um corpo bem cuidado, saudável, bonito e atraente, e as mulheres devem manter as mesmas rotinas de cuidado e ascese que os corpos cultuados nas academias. Obesidade não aparece mais como sinônimo do desleixo e da preguiça, mas como um corpo diferente que é cuidado e modelado de acordo com um novo padrão: o plus size.

Embora os blogs proponham um discurso que não apregoe um corpo magro como ideal, ainda assim sinalizam um ideal de corpo: o corpo cuidado. Se as roupas não se adequam, use cintas; se o rosto tem marcas, cubra-o com maquiagem; e, até mesmo, se desejar, emagreça. A aceitação do corpo obeso reproduzida pelos blogs de beleza plus size não eliminam a ideia de cuidado de si e dos deveres de cada indivíduo consigo mesmo. Ainda que não desejem mais alcançar os corpos das magérrimas modelos das revistas, elas se inspiram em modelos gordas, mas não menos investidas dos artefatos lançados pela cultura do consumo para o embelezamento do corpo. Estas mulheres continuam se esforçando para aperfeiçoar seus corpos, ainda que o ideal a ser alcançado tenha se modificado. 
Figura 7 - Foto da modelo Raphaella Tratsk, postada no blog Mulherão, considerada a atual revelação da moda plus size brasileira

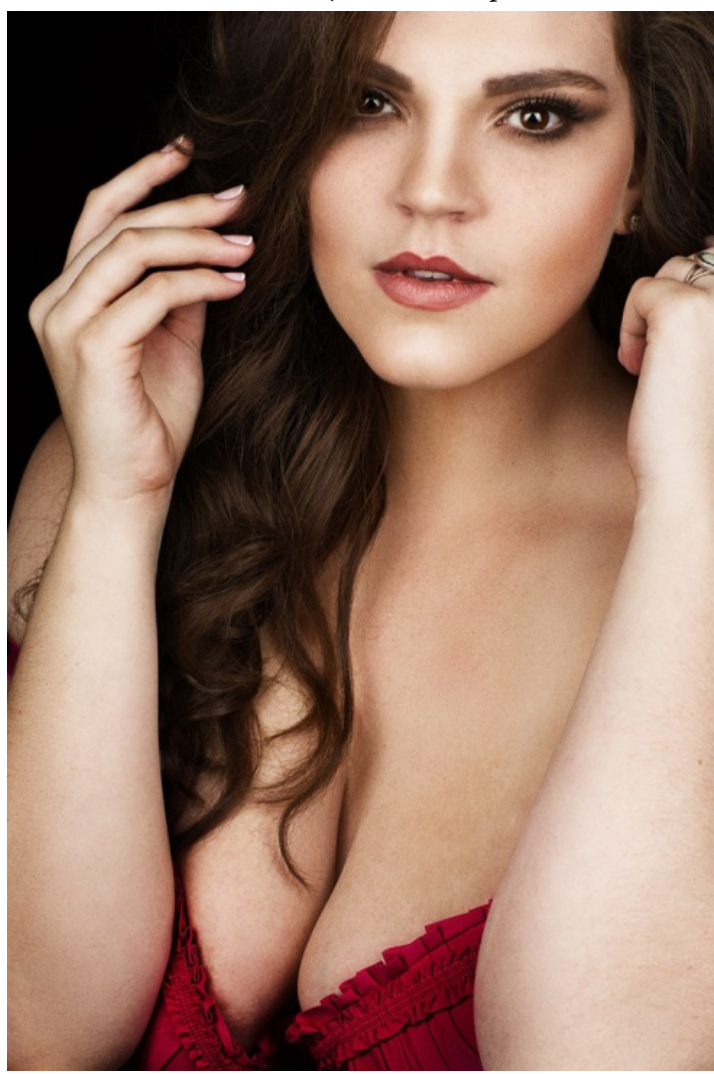

Fonte: https://blogmulherao.com.br. Acesso em: setembro de 2015.

Foucault (2004) teoriza que o cuidado de si trata de técnicas que permitem aos indivíduos manipularem seus corpos, almas, pensamentos e condutas de forma que modifiquem a si mesmos para alcançarem um certo modo de perfeição. Os blogs plus size, assim como outros blogs de beleza, outras mídias sociais e até a mídia hegemônica, difundem uma ética que converte o dever de cuidar de si em um prazer em cuidar de si. Os blogs convocam as mulheres a cuidarem de si mesmas e ressaltam o corpo como sinônimo da identidade, devendo ser amado e tratado. Foucault (2005) aponta que o cuidado de si implica em ações sobre si próprio, em que o corpo deve passar por um processo de autoconhecimento e governo.

Os blogs estimulam e desafiam suas leitoras a prestarem mais atenção a seus corpos, a não os rejeitar, mas conhecê-los para cuidarem melhor de si mesmas. Os blogs são repletos de dicas para situações da vida prática, tais como: "gordas podem 
ter parto normal?”3, "como ser uma gordinha sexy?"4, "9 dicas para quem está gorda e trava na hora do sexo"5, "qual o seu real manequim?"6 e, até mesmo "como ser gorda"7. Assim, ao longo das postagens, é possível perceber um processo visível que estimula as mulheres a conhecerem, explorarem, valorizarem e investirem em seus próprios corpos.

Denise Sant'Anna (1995, p. 123) aponta que cuidar de si implica "afinar a escuta em relação ao corpo próprio". As práticas do cuidado de si são uma forma de pedagogia do corpo e da alma (FOUCAULT, 2004), como um cuidado permanente de si mesmo. A questão do corpo e dos cuidados de si orientam uma grande parcela das postagens dos blogs. Por serem socialmente consideradas desleixadas, as mulheres obesas são muito mais desafiadas nos blogs a administrar a própria vida, seus corpos e sua saúde, pois precisam provar que são conhecedoras e capazes de agenciar o próprio organismo.

Há uma educação do corpo gordo, que é tanto pedagógica quanto política, produzindo discursos de verdade que pressupõem um ideal de corpo obeso, uma vez que os blogs posicionam os sujeitos dentro destes discursos, de modo diferente das mulheres não obesas, mas não a partir de uma significação negativa.

A imagem a seguir, como tantas outras, evidencia e destaca o corpo obeso. A exaltação da opulência, focada nas costas e nádegas, transmite a imagem de que a mulher gorda é portadora de um corpo desejável e fortalece a ideia de que o corpo acima do peso é motivo de orgulho e de amor próprio. A lingerie, a pele, a maquiagem e os cabelos são destacados de forma a modelar uma imagem que educa uma nova visão sobre o corpo obeso. Este é o ideal de corpo propagado pelos blogs: um corpo cuidado e esquadrinhado.

Os blogs plus size apresentam uma infinidade de práticas corporais que prometem melhorar a saúde, o bem-estar e autoestima. Trazem novos interesses e conhecimentos sobre os corpos obesos, que passam a ser cuidadosamente controlados, tal como descreve Foucault (1988, p. 25): “corrigiram-se aos poucos as posturas; uma coação calculada percorre cada parte do corpo, se assenhoreia dele, dobra o conjunto, torna-o perpetuamente disponível e se prolonga, cria-se o hábito", levando à formulação de um modelo de obesa cuidadosa, adaptada à orientação cultural hegemônica. As prescrições de cuidados com a beleza, com a alimentação, com os comportamentos, legitimam a ótica do cuidado, como um ato de responsabilidade perante si mesmas, e o descuido com o corpo é visto como uma forma de desleixo consigo mesmas.

3 Disponível em: <http://blogmulherao.com.br/20619/gravida-gorda-pode-ter-parto-normal/>. Acesso em: 19 dez. 2016.

4 Disponível em:<http://blogmulherao.com.br/16827/como-se-tornar-uma-gordinha-sexy/>. Acesso em: 19 dez. 2016.

5 Disponível em: <http://juromano.com/home/9-dicas-para-quem-esta-gorda-e-trava-na-hora-do-sexo $>$. Acesso em: 19 dez. 2016.

6 Disponível em: <http://belezasemtamanho.com/qual-o-seu-real-manequim/>. Acesso em: 19 dez. 2016.

7 Disponível em: <http://belezasemtamanho.com/como-ser-gorda/>. Acesso em: 19 dez. 2016. 
Figura 8 - Aline Zatar, para o site Paparazzo, republicado pelo blog Entre Topetes e Vinis

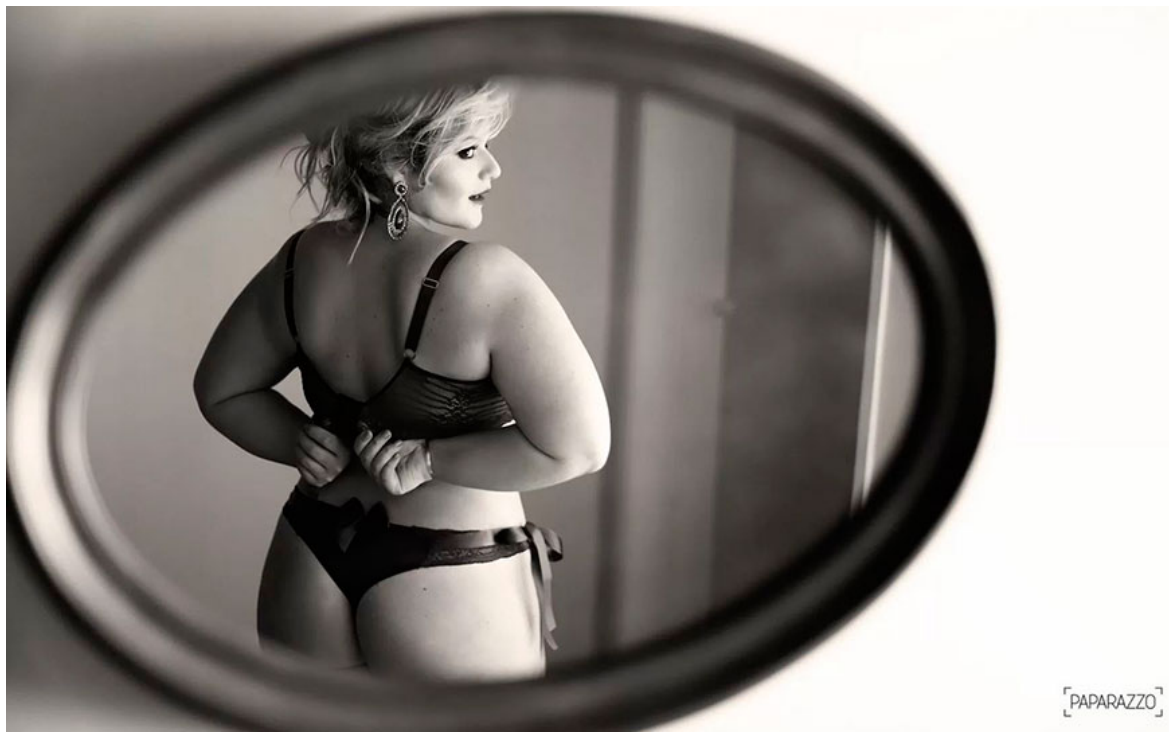

Fonte: https://juromano.com. Acesso em: março de 2015.

Figura 9 - Postagem no blog Mulherão, sobre não descuidar de si mesma

16 DE MARÇO DE 2011 22:47

Ser um mulherão com amor próprio não significa descuidar da saúde e engordar ainda mais

\section{UNCATEGORIZED}

Fazemos o Blog Mulherão para que todas as mulheres acima do peso se sintam bem consigo mesmas. Para que possam vislumbrar a felicidade independente de quanto sinalizam os cruéis ponteiros da balança. Entretanto (já disse isso várias vezes), ao recuperarmos nossa autoestima, voltamos a sorrir, a passear, a namorar, mas esquecemos de cuidar da saúde...

$\gg$ CONTINUE LENDO... 
Nos blogs plus size os corpos gordos são admirados, mas não sem a orientação de tentar otimizar suas potencialidades, cuidando de estrias, da flacidez, da hidratação, por exemplo, sem aceitar com resignação, os possíveis desgastes causados pelo excesso de peso. O corpo gordo é admirado desde que não exiba as marcas deste excesso. De acordo com Paula Sibilia (2004), trata-se de uma limpeza das impurezas que mantém o ideal de um corpo limpo e ascético, mesmo não estando no padrão hegemônico de magreza. A flacidez do corpo gordo não deve refletir uma "flacidez" na personalidade. Busca-se, a todo tempo, desvincular a imagem da obesidade a alguém que não sabe se controlar.

Figura 10 - Postagem estimulando as atividades físicas para mulheres obesas, no blog Entre Vinis e Topetes

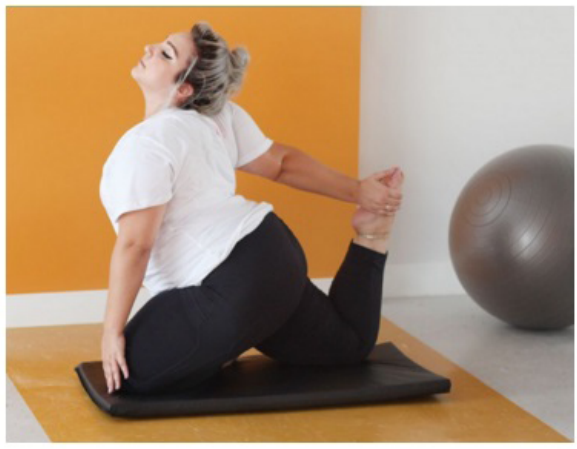

GORDA FITNESS, HOME, MODA, ONLINE, PUBLI - 2 MESES AGO Roupas de ginástica plus size: porque a gente pode ser uma gorda fitness!

Olá queridas, hoje o look é um pouco diferente: tem roupas de ginástica plus size. \o/ Bom, não é segredo para ningué.

Fonte: https://juromano.com. Acesso em: maio de 2015.

Estes discursos são característicos das sociedades de controle e reforçam a ideia de que a mulher é responsável pela própria vida e pelo próprio corpo. Essa dinâmica nos remete ao pensamento de Foucault (2002), sendo possível interpretá-la como correspondente a uma forma de adestramento mental e disciplinamento que normaliza o corpo e o ajusta aos padrões da sociedade de consumo contemporânea a partir das práticas disciplinares e das técnicas de cuidado de si. Os discursos sobre o cuidado de si são utilizados para sujeitar a subjetividade e normatizar as irregularidades, tendem a "controlar a ordem disciplinar do corpo e os acontecimentos aleatórios de uma multiplicidade biológica" (FOUCAULT, 1999, p. 302).

É possível perceber o poder disciplinador cotidianamente tentando conformar o corpo gordo. Nas sociedades contemporâneas, uma vigilância constante tenta normalizar os corpos, adequá-los a um determinado ideal de beleza, bem-estar, autocontrole e saúde através da disciplina e da biopolítica (FOUCAULT, 2004). Castro (2003) também aponta este processo de responsabilização e indica que os obesos são "pressionados moralmente", sendo acusados de falta de "controle de si". Para a autora: 
Os manuais de auto-ajuda, a mídia e os conselhos dos experts em saúde levam os indivíduos a acreditarem em que as imperfeições e defeitos corporais são resultados da negligência e ausência de cuidado de si. Com disciplina e boa vontade, qualquer um poderia alcançar uma aparência mais próxima do padrão de beleza vigente. Àqueles que não o alcançam é reservada a estigmatização, o desprezo e a falta de oportunidades (CASTRO, 2003, p. 72).

A importância de controle do próprio corpo constantemente reforçada pelos blogs parece estar relacionada a uma sensação de poder, já que, ao dedicar-se a um estilo de vida com investimento no próprio corpo, o sujeito considera-se seguro, equilibrado e dono de sua própria realidade, capaz de tornar-se aquilo que desejar. Entretanto, esta adequação ao sistema parece ser, na verdade, um assujeitamento de seu corpo e seu modo de vida aos desígnios sociais. Ao invés de representar a liberdade de si e de seus desejos, o cuidado com o corpo obeso significa um aprisionamento moral e físico aos padrões estabelecidos socialmente.

As necessidades e prazeres corpóreos parecem estar subjugados às imposições de uma ordem civilizada. Norbert Elias $(1990,1993)$ afirma que o corpo reflete esta estrutura social contemporânea em que se busca o condicionamento do inconsciente pela razão, por meio do autocontrole e repressão aos impulsos espontâneos. Assim, os desejos irracionais, como o de comer alimentos calóricos e evitar exercícios físicos, devem ser domesticados intimamente e substituídos por padrões de comportamento ascéticos e ponderados, uma vez que a gestão social do corpo se dá por processos de autocontrole. Os corpos, comportamentos e estilos de vida devem ser submetidos a uma racionalização e consciência objetiva.

O processo civilizador moderno se reflete no corpo através da coibição da espontaneidade, baseado em uma dualidade que privilegia os aspectos mentais em detrimento do biológico. Este dualismo, pensado por Platão e Descartes, é central na modernidade e divide os sujeitos em uma subjetividade racional e um corpo material que aprisiona a mente. Segundo Le Breton (2003, p. 18), "os anatomistas antes de Descartes e da filosofia mecanicista fundam um dualismo que é central na modernidade e não apenas na medicina, aquele que distingue, por um lado, o homem, por outro seu corpo". Descartes (1995) acreditava que o corpo deveria ser excluído do processo de produção do conhecimento, já que para ele a razão deveria ser separada de "perturbadores sensíveis", a fim de se alcançar um conhecimento.

Os blogs plus size propõem a desconstrução da imagem carregada pelo obeso, de ser aquele que não conseguiu conter seus impulsos, que fracassa na busca por um corpo perfeito e permite que seus desejos primários se estabeleçam em detrimento de seu pensamento racional. A aparência corporal é fortemente associada ao seu caráter moral, pois corresponde à forma como este se apresenta cotidianamente, e cada vez mais, é representado pela forma de cuidado com o corpo. De tal maneira, o que os blogs buscam mostrar é que, ainda que estejam fora do mainstream, estão dentro de um padrão: o plus size. 


\section{Considerações finais}

Na esteira de Mauss, Le Breton (2006) afirma que a propriedade primária da aparência se relaciona com as modalidades simbólicas de organização social e cultural à qual o sujeito é pertencente. Assim, a apresentação física de si corresponde socialmente à apresentação moral do indivíduo, determinando a quem serão direcionados os preconceitos e marginalizações. Neste sentido, percebemos que o obeso tende a buscar uma aparência mais próxima do padrão, eliminando, camuflando e escondendo as características que lhe distanciam do modelo aceito, renegando sua própria corporeidade e reforçando ainda mais os estereótipos relacionados à obesidade.

$\mathrm{Na}$ composição dessa nova imagem da mulher obesa, a definição de beleza e cuidado pessoal acompanha as demandas das sociedades de consumo. Essas mulheres buscam ser bem-sucedidas na carreira, nos relacionamentos, na maternidade, sempre elegantes, inteligentes e belas. Os blogs criam a imagem de uma mulher obesa realizada, forte, corajosa, participativa, atraente, constituindo um importante discurso que produz distintas identificações. Os blogs são, portanto, uma tecnologia de autogoverno que politiza o corpo obeso e cria "novos" discursos sobre a obesidade dentro da própria lógica das sociedades de consumo.

Em conclusão, podemos afirmar que os blogs plus size têm se destacado por questionar os padrões de beleza que relacionam magreza à perfeição corporal, especialmente no que se refere à indústria de moda e cosméticos. Contudo, embora estes blogs apareçam como espaços para uma mudança de valores em relação ao corpo, resultam em nortear um certo nicho de mercado, voltado para o público feminino. $\mathrm{O}$ mote de que todos os corpos devem ser belos parece, em um primeiro momento, libertar as mulheres das amarras sociais, entretanto, os discursos acabam muitas vezes reificando a imagem feminina e a estetização da beleza, apenas ampliando a gama de corpos considerados “aceitáveis".

Nesses blogs, o consumo medeia a abertura dos espaços sociais para as mulheres obesas e o novo olhar sobre esse segmento de consumidoras. Ainda que lutem para que seus corpos sejam aceitos, os discursos das mulheres em blogs plus size continuam a manter ideais difíceis de serem alcançados, estimulando uma vida ascética e regrada, sem considerar diferenças culturais, étnicas, sexuais e econômicas, por exemplo. Os blogs assumem um papel mercadológico de manter o controle sobre os corpos obesos. Se antes estes eram considerados outsiders, por meio do cuidado de si e do consumo se tornaram parte do sistema. O consumo, a partir destes discursos, ganha conotação de ativismo e de consumo consciente, porém, em seu escopo, estes espaços virtuais reiteram, na verdade, as representações daquilo que combatem: um corpo que sofre na busca de adaptar-se a um padrão socialmente estabelecido. 


\section{Referências}

AMARAL, Adriana; RECUERO, Raquel; MONTARDO, Sandra (Orgs.). Blogs.com: estudos sobre blogs e comunicação. São Paulo: Momento editorial, 2009.

BAUMAN, Zygmunt. Vida para consumo: a transformação das pessoas em mercadoria. Rio de Janeiro: Zahar, 2008.

CASTELLS, Manuel. A sociedade em rede. São Paulo: Paz e Terra, 1999.

CASTRO, Ana Lúcia de. Culto ao corpo e sociedade: mídia, estilos de vida e cultura de consumo. São Paulo: Annablume/Fapesp, 2003.

Imagens do corpo e cultura de consumo. ComCiência, v.99, p. 1-4, 2008.

CECHIN, Michelle Brugnera Cruz; SILVA, Thaise. A boneca Barbie na cultura lúdica: brinquedo, infância e subjetivação. Zero-a-seis, Florianópolis, v. 1, p. 20-42, 2012.

COBO ROMANÍ, Cristóbal.; PARDO KUKLINSKI, Hugo. Planeta Web 2.0: inteligencia colectiva o medios fast food. Barcelona, México, DF: Grup de Recerca d'Interaccions Digitals, Universitat de Vic. Flacso México, 2007.

DEL PRIORI, Mary. Corpo-a-corpo com a mulher: pequena história das transformações do corpo no Brasil. São Paulo: SENAC, 2000.

ELIAS, Norbert. O processo civilizador: uma história dos costumes. Rio de Janeiro: Zahar, 1990.

. O processo civilizador: formação do Estado e civilização. Rio de Janeiro: Zahar, 1993.

FOUCAULT, Michel. História da sexualidade 1: a vontade de saber. Rio de Janeiro: Graal, 1988. . A arqueologia do saber. Rio de Janeiro: Forense, 1996.

Vigiar e punir. 25. ed. Petrópolis: Vozes, 2002.

Microfísica do poder. São Paulo: Graal, 2004.

História da sexualidade 3: o cuidado de si. Rio de Janeiro: Graal, 2005.

GOLDENBERG, Mirian; RAMOS, Marcelo Silva. A civilização das formas: o corpo como valor. In: GOLDENBERG, Mirian (Org.). Nu e vestido: dez antropólogos revelam a cultura do corpo carioca. Rio de Janeiro: Record, 2002. p. 19-39.

GUATTARI, Félix; ROLNIK, Suely. Micropolíticas: cartografias do desejo. Petrópolis: Vozes, 2000.

INGLIS, Fred. Breve história da celebridade. Rio de Janeiro: Versal Editores, 2012.

LE BRETON, David. Adeus ao corpo: antropologia e sociedade. Campinas: Papirus, 2003.

A sociologia do corpo. Petrópolis, RJ: Vozes, 2006.

MARTÍN-BARBERO, Jésus. Procesos de comunicación y matrices de cultura: itinerário para salir de la razón dualista. México: Gustavo Gili, 1987.

MAUSS, Marcel. As técnicas do corpo. In: Sociologia e Antropologia. São Paulo: Cosac Naify, 2003, p. 399-422.

NOVAES, Joana de Vilhena. O intolerável peso da feiura: sobre as mulheres e seus corpos. Rio de Janeiro: PUC/GARAMOND, 2005.

ROJEK, Chris. Celebridade. Rio de Janeiro: Rocco, 2008.

ROUSSO, Henry. A memória não é mais o que era. In: FERREIRA, Marieta de Moraes; AMADO, Janaína. Usos e abusos da história oral. 3. ed. Rio de Janeiro: FGV, 2000, p. 93-101.

SANT’ANNA, Denise Bernuzzi. Políticas do corpo, elementos para uma história das práticas corporais. São Paulo: Estação Liberdade, 1995.

SOARES, Carmem. Corpo e história. Campinas: Autores Associados, 2001. 
SIBILIA, Paula. O pavor da carne: risco da pureza e do sacrifício no corpo-imagem contemporâneo. Revista Famecos, Porto Alegre, n. 25, dez., p. 68-84, 2004.

SOARES, C. L. Imagens da educação no corpo: estudo a partir da ginastica francesa no século XIX. 3. ed. Campinas, SP: Autores Associados, 2005.

SOARES, Rosângela de Fátima Rodrigues; MEYER, Dagmar Estermann. O que se pode aprender com a "MTV de papel" sobre juventude e sexualidade contemporâneas? Revista Brasileira de Educação, n. 23, p. 136-148, 2003.

ULLMAN, Dora. O peso da felicidade: (ser magro é bom, mas não é tudo). Porto Alegre: RBS Publicações, 2004.

WILLIAMS, Raymond. Marxismo e Literatura. Rio de Janeiro: Zahar, 1979.

Recebido em 13/10/2017

Aceito em 12/011/2018 